\title{
Tuber fulgens Quél., A New Record for Turkish Truffles
}

\author{
Ilgaz Akata ${ }^{1, a, *}$, Mustafa Sevindik ${ }^{2, b}$, Ergin Şahin $^{3, c}$ \\ ${ }^{I}$ Department of Biology, Faculty of Science, Ankara University, 06100 Ankara, Turkey \\ ${ }^{2}$ Department of Food Processing, Bahçe Vocational School, Osmaniye Korkut Ata University, 80000 Osmaniye, Turkey \\ ${ }^{3}$ Department of Biology, Faculty of Science, Ankara University, 06100 Ankara, Turkey \\ *Corresponding author

\begin{tabular}{l|l} 
A R T I C L E I N F O & A B S T R A C T \\
\hline $\begin{array}{l}\text { Research Article } \\
\text { Received : 13/09/2020 } \\
\text { Accepted : } 31 / 10 / 2020\end{array}$ & $\begin{array}{l}\text { Tuber samples were collected from Kirklareli province on the } 10^{\text {th }} \text { of August } 2020 \text { and they are } \\
\text { identified by implementing both traditional methods and molecular phylogenetic analysis using the } \\
\text { rDNA sequences including Internal Transcribed Spacer (ITS) and 28S Ribosomal Large Subunit } \\
\text { (LSU) regions. By taking into account the high sequence similarity between the collected samples } \\
\text { (ANK Akata 7351) and the truffle species Tuber fulgens Quél. the collected specimen was regarded } \\
\text { as } T \text {. fulgens and the morphological data also consolidated this finding. As a result, T. fulgens was } \\
\text { reported for the first time from Turkey. A short description of the newly reported species is given } \\
\text { along with its macro and microphotographs, and spore images taken by a scanning electron } \\
\text { microscope (SEM). Additionally, ITS and LSU rDNA based evolutionary history of the specimen } \\
\text { is provided with phylogenetic trees. }\end{array}$ \\
Keywords: &
\end{tabular}

Tuber

Hypogean fungi

New record

Turkey

Truffle species

\section{Introduction}

Tuber, also known as truffles, is an ectomycorrhizal hypogean genus of the family Tuberaceae belonging to the order Pezizales within the division Ascomycota. The genus includes over 180 widespread species which have highly valued, gastronomic importance and they are regarded as the diamond of the kitchen. Tuber species are known to establish ectomycorrhizal associations with both gymnosperm and angiosperms such as pine, fir, beech, birch, common hazel, poplar, and willow (Patel, 2012; Wan et al., 2017). Members of the genus are mainly characterized by globose to lobed, hypogenous and sessile ascomata sometimes with basal mycelial tuft, solid and firm gleba usually marbled, smooth or warted peridium, globose, sub globose or pear-shaped asci usually with 1-6 spores, ornamented spores with warts, spines or ridges (Hansen and Knudsen, 2000).
T.fulgens grows on calcareous soil from summer to winter and it is associated with various deciduous trees such as oak and hornbeam (Lawrynowicz, 2009). Considering the literature on Turkish Tuber (Castellano and Türkoğlu, 2012; Elliot et al., 2016; Gezer et al., 2014; Öztürk et al., 1997; Sesli and Denchev, 2014; Şen et al., 2016; Türkoğlu and Castellano, 2014), up until now, 8 species (Tuber aestivum (Wulfen) Spreng., T. brumale Vittad., T. excavatum Vittad., T. ferrugineum Vittad., T. mesentericum Vittad., T. nitidum Vittad., T. puberulum Berk. \& Broome and T. rufum Picco.) which were identified based on morphological characteristics have been reported from Turkey. However, there was not any report of Tuber fulgens Quél. in Turkey. The purpose of this paper is to contribute to Turkish Tuber. 


\section{Material and Methods}

\section{Morphological Study}

Tuber specimens were collected from Kirklareli provinces (Turkey) in 2019. In their natural habitat, the macroscopic and ecological characteristics of the specimens were noted. At the fungarium, microscopic features were scrutinized using both binocular light microscope (LM) and scanning electron microscope (SEM). In light microscopy, measurements were repeated for about 30 times under a light microscope (Euromex Oxion Trinocular microscope). Each microscopic structure was examined with 100X magnification rates and the compiled data were assessed statistically. For SEM, pieces of mass inside the gleba were fixed on stubs using double-sided sticky tape, coated with gold particles, and visualized using an EVO 40XVP (LEO Ltd., Cambridge, UK) scanning electron microscope with an accelerating voltage of $20 \mathrm{kV}$. Fungarium materials were prepared from the identified specimens and deposited into Ankara University Herbarium (ANK).

\section{Determination of the ITS and LSU rDNA Sequences}

For the genomic DNA isolation from ANK Akata 7351, CTAB method was utilized as described elsewhere (Rogers and Bendich, 1994). The isolated genomic DNA was spectrophotometrically (Nanodrop Lite Thermo Scientific) analyzed for the quality and quantity measurements and then it was utilized in a polymerase chain reaction as the template to amplify the Internal Transcribed Spacer (ITS) and 28S Ribosomal Large Subunit (LSU) rDNA regions. PCR amplification of the ITS and LSU rDNA regions was conducted using the ITS1/ITS4 and LR5/LROR universal primer couples as previously reported (Stielow et al., 2015). The presence of amplicons was electrophoretically confirmed as single and clear bands on an agarose gel and later they were purified with Expin Gel, PCR, and CleanUp SV Kit (GeneAll) and sequenced with Sanger dideoxy sequencing method. Same ITS1/ITS4 and LR5/LROR primer couples were utilized for the sequencing PCR performed using the BigDye ${ }^{\mathrm{TM}}$ Direct Cycle Sequencing Kit (Thermo Fisher Scientific) and the fragment analyses were conducted using ABI Prism 3130 Genetic Analyzer. Agarose gel electrophoresis and the Sanger sequencing were carried out as described elsewhere (Chen et al., 2014).

\section{Molecular Phylogeny}

For the molecular phylogeny, the sanger reads obtained from ITS1/ITS4 and LR5/LROR primer couples were assembled using DNAMAN Version 10 sequence assembly software (Lynnon Corporation) and BLASTn analyses were performed with the assembled sequences for the identity rate search. Based on these BLAST analyses, the in-group and the out-group members were retrieved from NCBI GenBank for the phylogenetic analyses. The assembled sequences and the nucleotide sequences of the retrieved in-group and outgroup members were aligned using the ClustalW algorithm of MEGAX software (Kumar et al., 2018). The phylogenetic trees demonstrating the evolutionary history of ANK Akata 7351 were constructed using the Maximum Likelihood method and K2 nucleotide substitution model with a gamma distribution (Kimura, 1980). The bootstrap method was implemented for the accuracy estimation using 1000 bootstrap replicates (Felsenstein, 1985).

\section{Results}

Tuber fulgens Quél. (1880), Figure 1-2)

Macroscopic and Microscopic Features

Ascomata 20-30 mm, hypogeous, subglobose, with deep basal cavities, rugulose, orange to reddish-brown. Gleba solid, firm, pale brown with whitish veins radiating from the cavity, often with orange-red spots. Peridium 250$350 \mu \mathrm{m}$ thick, bright orange-brown to reddish-brown. Odor and taste mild. Asci 105-140 × 95-110 $\mu \mathrm{m}$, subglobose to ellipsoid, sessile or short stipitate, and 1-4-spored. Ascopores 45-55 $\times 35-45 \mu \mathrm{m}$, globose to subglobose, yellow to yellowish-brown, with alveolate-reticulate ornamentation with high walls.

Material examined: Turkey-Kırklareli, in oak and hornbeam mixed forest, $400 \mathrm{~m}, 41^{\circ} 44^{\prime}, \mathrm{N}, 27^{\circ} 35^{\prime} \mathrm{E}, 10$ August, 2020, ANK Akata 7351.

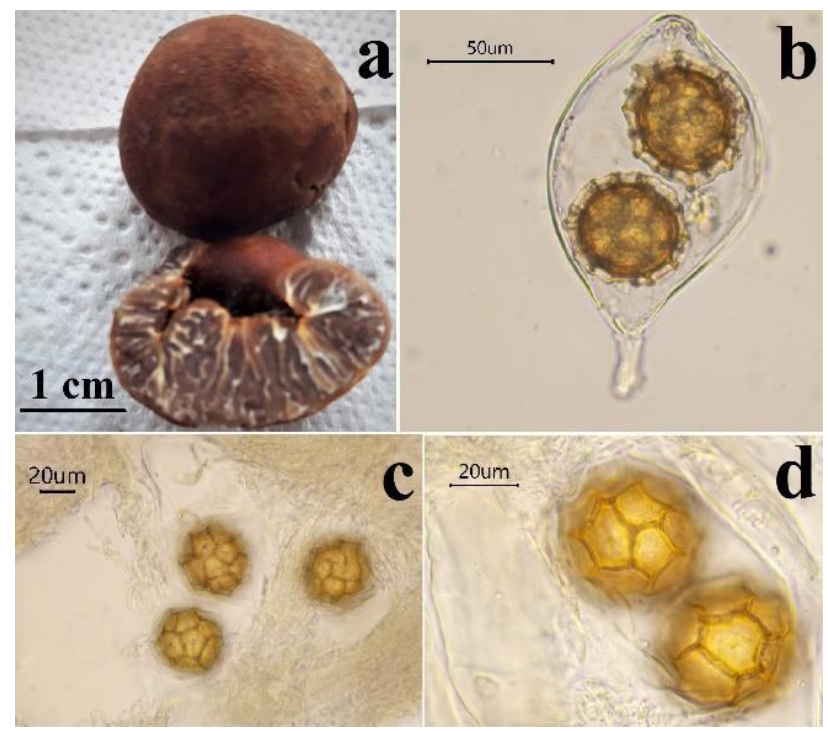

Figure 1. Tuber fulgens: a. ascomata, b. spores in an ascus (under LM), c,d. spores (under LM).

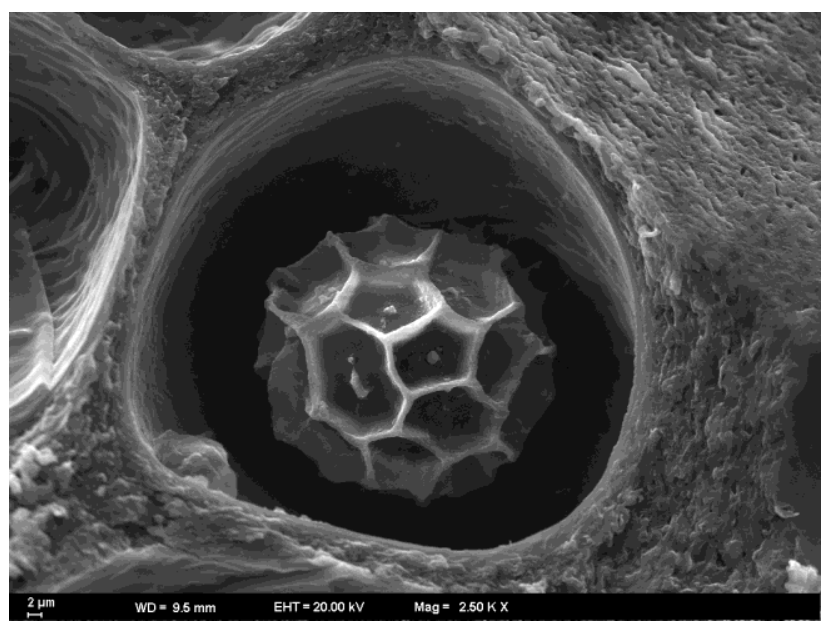

Figure 2. Tuber fulgens: a spore in ascus visualized by a scanning electron microscope (SEM).

\section{Molecular Phylogeny of ANK Akata 7351}

The ITS and LSU rDNA sequences of ANK Akata 7351 obtained from Sanger sequencing were deposited into NCBI GenBank with the accession numbers of MT984247.1 and MT982616.1 respectively. 


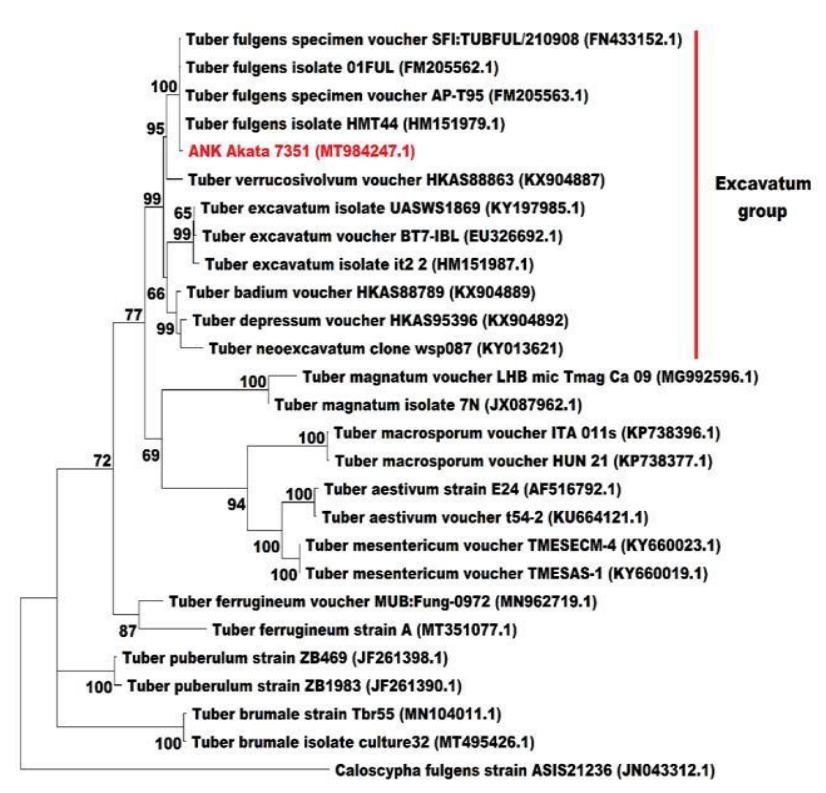

0.5

Figure 3. The Maximum Likelihood tree revealing the phylogenetic relationships of 14 fungal species estimated from the nuclear ITS rDNA region. Percentage bootstrap values $(\geq 50)$ were indicated for each branch. All of the sequences included in the phylogenetic analysis were retrieved from GenBank except for ANK Akata 7351. Caloscypha fulgens were included as the outgroup sample in the phylogenetic analysis. GenBank accession numbers are also given. The scale bar (lower left) represents a genetic distance of 0.5 .

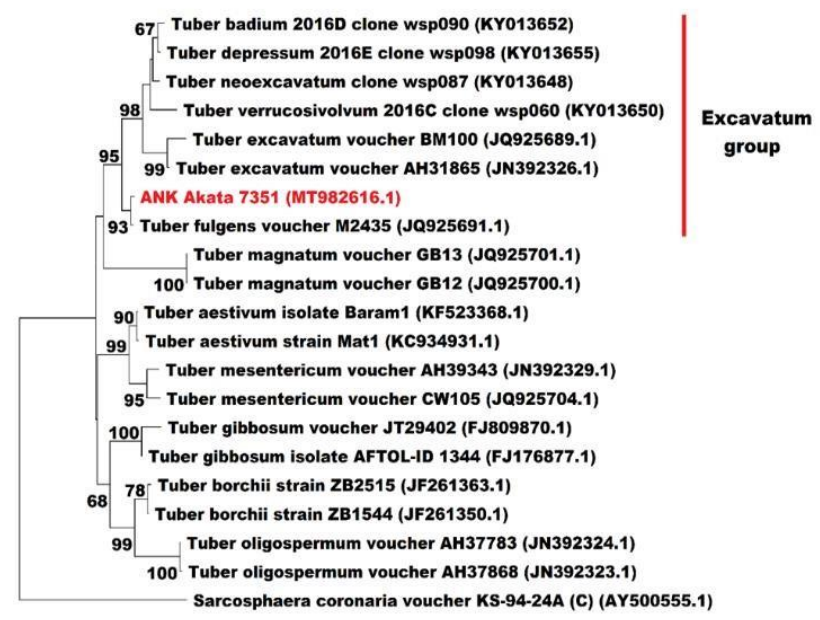

$\overrightarrow{0.05}$

Figure 4. The Maximum Likelihood tree revealing the phylogenetic relationships of 13 fungal species estimated from the nuclear LSU rDNA region. Percentage bootstrap values $(\geq 50)$ were indicated for each branch. All of the sequences included in the phylogenetic analysis were retrieved from GenBank except for ANK Akata 7351. Sarcosphaera coronaria was included as the outgroup samples in the phylogenetic analysis. GenBank accession numbers are also given. The scale bar (lower left) represents a genetic distance of 0.05 .
In phylogenetic analysis of ANK Akata 7351, considering the BLAST search results of the specimen`s nuclear ITS rDNA sequence, the various members of the genus Tuber from the family Tuberaceae were used as the ingroup sequences and the nuclear ITS rDNA sequences of Caloscypha fulgens (Pers.) Boud. from the family Caloscyphaceae was selected for the outgroup sequence. On the other hand, for the LSU rDNA based phylogenetic analysis of ANK Akata 7351, LSU sequences of various members of the genus Tuber were used as the ingroup sequences, and the LSU sequence of Sarcosphaera coronaria (Jacq.) J. Schröt. from the family Pezizaceae was selected as the outgroup sequence.

As a result of the phylogenetic analysis conducted with the ITS sequences including from ANK Akata 7351, a highly supported distinct clade came out (Figure 3). This clade, named as Excavatum group, included different isolates of Tuber fulgens and the specimen ANK Akata 7351 along with different isolates of Tuber excavatum and closely related, recently described Tuber species such as $T$. verrocusivolvum, T. badium, $T$. depressum, and $T$. neoexcavatum (Figure 3). On the other hand, Caloscypha fulgens fell into a distinct branch separate from the ingroup species and formed an outgroup as predicted. The BLAST analysis implemented with the nuclear ITS rDNA sequence of ANK Akata 7351 revealed identity rates as high as $99.23 \%$ between the specimen and different isolates of $T$. fulgens. The phylogenetic analyses performed herein, further strengthen the close identity relationship of this specimen with T. fulgens with a bootstrap value of $100 \%$.

As a result of the phylogenetic analysis performed with the LSU sequences including from ANK Akata 7351, again a highly supported distinct clade (Excavatum group) came out (Figure 4). This clade also included one isolate of Tuber fulgens and the specimen ANK Akata 7351 along with different isolates of Tuber excavatum and closely related, recently described Tuber species such as $T$. verrocusivolvum, $T$. badium, $T$. depressum, and $T$. neoexcavatum (Figure 4). On the other hand, Sarcosphaera coronaria fell into a distinct branch separate from the ingroup species and formed an outgroup as predicted. The BLAST analysis performed with the nuclear LSU rDNA sequence of ANK Akata 7351 revealed identity rates as high as $99.21 \%$ between the specimen and one isolate of $T$. fulgens. The phylogenetic analyses performed herein, further strengthen the close identity relationship of this specimen with T. fulgens with a bootstrap value of $93 \%$.

\section{Discussion}

Although T. fulgens resembles other excavatum group members (Tuber badium S.P. Wan, T. depressum S.P. Wan, T. excavatum Vittad., T. neoexcavatum L. Fan \& Yu $\mathrm{Li}$ and T. verrucosivolvum S.P. Wan) in terms of its macro and micromorphology, its distinguishable characteristics are orange-brown ascomata and a relatively single type of ascospores (globose to subglobose) (Fan et al., 2013; Lange, 1956; Wan et al., 2017). However, ITS and nrLSU rDNA regions-based molecular phylogeny and SEM images of spores can help distinguish $T$. fulgens from other excavatum group members. 
For the precise identification of fungal species, conventional methods relied on morphological data may not always sufficient. For this reason, conserved regions of genomic DNA such as nrITS, and nrLSU, as well as sequences of protein-coding genes, are utilized for molecular taxonomic studies for the last few decades (Raja et al., 2017). Besides, ITS and LSU are two of the most generally used DNA barcoding markers for fungi and thus confers precious information for molecular phylogenetic studies. Therefore, we employed nuclear ITS and LSU rDNA sequences for the molecular identification of ANK Akata 7351. Nuclear ITS and LSU rDNA-based molecular phylogeny exhibited almost $100 \%$ identity between Tuber fulgens and the specimen (GenBank ID: MT984247.1 and MT982616.1 for ITS and LSU rDNA regions respectively) (Figure 3 and 4).

\section{Conclusion}

With this study, T.fulgens was reported for the first time from Turkey and it is the $9^{\text {th }}$ reported Tuber species for Turkish truffles. The morphological data obtained from the specimen ANK Akata 7351 corresponded to the description of T. fulgens. Additionally, the ITS and LSU rDNA based molecular phylogenetic studies of the specimen further consolidated the accuracy of the conventional identification of ANK Akata 7351.

\section{Acknowledgments}

We thank Ziyafet Arslan for the valuable effort he made during the field studies.

\section{References}

Castellano MA, Türkoğlu A. 2012. New Records of Truffle Taxa in Tuber and Terfezia from Turkey. Turk J Bot, 36: 295-298.

Chen L, Cai Y, Zhou G, Shi X, Su J, Chen G, Lin K 2014. Rapid Sanger sequencing of the 16S rRNA gene for identification of some common pathogens. PloS one 9(2): e88886

Elliot TF, Türkoğlu A, Trappe MT, Yaratanakul Güngör M. 2016. Turkish Truffles 2: Eight New Records from Anatolia. Mycotaxon, 131: 439-453

Fan L, Cao JZ, Li Y. 2013. A reassessment of excavated Tuber species from China based on morphology and ITS rDNA sequence data. Mycotaxon, 124(1): 155-163.

Felsenstein J. 1985. Confidence limits on phylogenies: An approach using the bootstrap. Evolution, 39:783-791.

Gezer K, Kaygusuz O, Çelik A, Işıloğlu M. 2014. Ecological Characteristics of Truffles Growing in Denizli Province, Turkey. Journal of Food, Agriculture \& Environment, 12: $1105-1109$.

Hansen L, Knudsen H. 2000. Nordic Macromycetes. Nordsvamp, Copenhagen, Denmark.
Kimura M. 1980. A simple method for estimating evolutionary rate of base substitutions through comparative studies of nucleotide sequences. Journal of Molecular Evolution, 16: 111-120.

Kumar S, Stecher G, Li M, Knyaz C, Tamura K. 2018. MEGA X: molecular evolutionary genetics analysis across computing platforms. Mol Biol Evol, 35: 1547-1549.

Lange M. 1956. Danish hypogeous fungi. Dansk Botanisk Arkiv, 16: $1-48$.

Ławrynowicz M. 2009. Four Tuber species accompanying $T$. mesentericum in natural sites in Poland. In Anales del Jardín Botánico de Madrid, 66(1):145-149

Öztürk C, Kaşık G, Toprak E. 1997. Ascomycetes Makrofunguslarından Türkiye İçin İki Yeni Kayıt. Ot Sistematik Botanik Dergisi, 4: 53-56.

Patel S. 2012. Food, health and agricultural importance of truffles: a review of current scientific literature. Current Trends in Biotechnology and Pharmacy, 6(1): 15-27.

Raja HA, Miller AN, Pearce CJ, Oberlies NH. 2017. Fungal Identification Using Molecular Tools: A Primer for the Natural Products Research Community. J Nat Prod, 80(3): 756-770.

Rogers SO, Bendich, AJ. 1994. Extraction of total cellular DNA from plants, algae and fungi. In Plant molecular biology manual. Springer, Dordrecht, 183-190.

Sesli E, Denchev CM. 2014. Checklists of the myxomycetes, larger ascomycetes, and larger basidiomycetes in Turkey. Mycotaxon, 106: 65-67 [6th ed. Mycotaxon Checklists Online. 136 p. http://www.mycotaxon.com/resources/ checklists/sesli-v106-checklist.pdf].

Stielow JB, Lévesque CA, Seifert KA, Meyer W, Irinyi L, Smits D, Renfurm R, Verkley GJM, Groenewald M, Chaduli D, Lomascolo A, Welti S, Lesage-Meessen L, Favel A, Al-Hatmi AMS, Damm U, Yilmaz N, Houbraken J, Lombard L, Quaedvlieg W, Binder M, Vaas LAI, Vu1 D, Yurkov A, Begerow D, Roehl O, Guerreiro M, Fonseca A, Samerpitak K, van Diepeningen $\mathrm{AD}$, Dolatabadi S, Moreno LF, Casaregola S, Mallet S, Jacques N, Roscini L, Egidi E, Bizet C, GarciaHermoso D, Martín MP, Deng S, Groenewald JZ, Boekhout T, de Beer ZW, Barnes I, Duong TA, Wingfield MJ, de Hoog GS, Crous PW, Lewis CT, Hambleton S, Moussa TAA, Al-Zahrani HS, Almaghrabi OA, Louis-Seize G, Assabgui R, McCormick W, Omer G, Dukik K, Cardinali G, Eberhardt U, de Vries M, Robert V. 2015. One fungus, which genes? Development and assessment of universal primers for potential secondary fungal DNA barcodes. Persoonia: Molecular Phylogeny and Evolution of Fungi, 35: 242-263.

Şen İ, Allı H, Civelek HS. 2016. Checklist of Turkish truffles. Türk Yaşam Bilimleri Dergisi 1(2): 103-109.

Türkoğlu A, Castellano MA. 2014. New Records of Some Ascomycete Truffle Fungi from Turkey. Turk J Bot. 38: 406416.

Wan SP, Xu WJ, Tan N, Wang Y, Zheng Y, Yu F. 2017. Three Excavatum species Tuber badium, T. depressum and $T$. verrucosivolvum from Sichuan Province, China. Phytotaxa, 296(3): 228-238. 